\title{
Sustainable Development and Social Justice: Conflicting Urgencies and the Search for Common Ground in Urban and Regional Planning
}

\author{
SCOTT D. CAMPBELL, PHD
}

Volume 1, Fall 2013

DOI: http://dx.doi.org/10.3998/mjs.12333712.0001.007

\section{ABSTRACT}

This essay examines urban planning's recent engagement with two social movements - sustainability and social justice — and the field's efforts to simultaneously pursue both impulses. What arises from the juxtaposition of these two lofty goals? I develop three arguments. First, rather than prematurely speaking of a convergence between environmental sustainability and social justice, planners might better approach this encounter as a productive tension of two still incongruent movements. Second, before planners can negotiate a merger of sustainability and social justice, they first ought to directly confront the political imbalance between the two: middle-class environmental interests typically trump the interests of the poor and marginalized, too often leading to an exclusionary sustainability of privilege rather than a sustainability of inclusion. Third, despite the perhaps inevitable criticisms of immeasurability and vagueness, sustainability has endured as a central principle in urban planning because its oppositional engagement with social justice and economic development continually reinvigorates sustainability planning, keeps the term relevant and inclusive, and grants the task of urban planning greater urgency.

Proponents of sustainability frequently emphasize the importance of adding social justice to their efforts, while social justice advocates increasingly incorporate the ideas of sustainability into their own agendas. These bilateral efforts might suggest a convergence of two political movements-a coming marriage of environmental and social politics. But such integration won't be an easy or automatic process: each 
of the two movements has its own distinct histories and trajectories, deeply embedded in disparate ideologies, priorities and institutions. The sustainability and social justice movements may be coming closer together, yet much still divides them into two separate conversations that frequently overhear each other without easily merging. How do we describe the complex terrain at the confluence of the social justice movement and the sustainability movement - two movements that even separately elude simple definition? This paper analyzes the promises and obstacles of combining social justice and environmental sustainability using the example of urban planning research and practice, a case study that may well speak to other disciplines.

Five years ago, the faculty of the University of Michigan's Urban and Regional Planning Program formally identified sustainability and social justice as the two central ideas to organize teaching and target new directions for collaborative research. Though in retrospect the outcome may have seemed predictable and selfevident, the discussion leading up to the selection was animated and could have headed in several divergent directions: perhaps the selection of a single core idea (with the other subordinate), or the diluted expansion of the list, including sustainability and equity with other planning values such as efficiency, aesthetics, rationality or resilience. (And the discussion raised an even more fundamental question: should a graduate professional program embrace any normative stance at all?) The eventual selection of both topics was ambitious: they aspirationally represent a coequal combination of sustainability and social justice. The paired choice also reflects institutional compromise and inclusiveness among a diverse planning faculty: some come from a land use, landscape ecology and environmental planning background, while others bring the culture and values of community development and social equity, informed by the civil rights, labor and feminist movements. These two foundations of planning have separate origins, heroes and core values: interlocking these two separate histories into a shared agenda will be a challenging, long-running task.

The planning faculty has subsequently asserted these two themes through coursework, research, and admissions materials, and the result has both catalyzed discussion and given the program's mission greater clarity. Though there is no single, consensus description of either theme, for this essay I will define social justice as the explicit recognition of structural inequalities in the world (along class, race, gender, institutional and other lines) and therefore the need for proactive, structural programs to counteract these inequalities. I define sustainable development as a broad collection of principles and corresponding planning policies to bring urban economies and local land development in closer alignment with the long-term limits of the landscape to support urban settlements, absorb the wastes of human activities 
and enable non-human flora and fauna to thrive. For urban and regional planners, the emphasis of both social justice and sustainability has been explicitly spatial, with particular focus on neighborhoods, on struggling inner cities, and on the disparities both between central cities and suburbs and between the global north and south. The two priorities of social justice and sustainability are, in essence, collectively confronting the damaging consequences of "uneven development": both in the standard political economic sense (the uneven distribution of economic resources) and in the environmental sense (an uneven development of human versus non-human habitats, resource use, and allocation of environmental hazards).

The field of urban planning is certainly not alone in juxtaposing questions of equity and ecology. For environmental scholars and professionals, this merger of environmentalism and social justice has a readily apparent answer: the burgeoning field of "environmental justice" (EJ). Indeed, readers of this essay may impatiently exclaim that the environmental justice community has been diligently and fruitfully working on this sustainability/social justice synthesis for several decades (see, for example, Bryant 1995; Bryant and Mohai 1992; Hofrichter 1993; Agyeman 2005; Bullard 1994; Taylor 2009), and puzzle at urban planners' efforts to reinvent the wheel rather than simply importing this considerable EJ knowledge over to planning.

The explanation for planning taking its own path may be complex, arising not only from the planning discipline's stubborn tendency to create its own indigenous theory (rather than adopting from others), but also from the incomplete applicability of the EJ paradigm for urban planning. Yes, urban planners with an interest in either equity or ecology greatly admire and embrace the values of environmental justice and view it as a critical expansion of both mainstream environmentalism and social justice. Nevertheless, urban planning is distinct from environmental science/ policy and has its own specific demands. Planners focus their work on the broader distributional consequences of urban land uses, local economic activity, municipal governance, housing, transportation access and public services, rather than EJ's more specific focus on the uneven distribution of environmental costs/benefits and the unfair implementation of environmental regulations. Planning's central focus on the metropolitan development process has arguably steered the profession towards an urbanized, municipally focused version of sustainable development - rather than the "environmental justice" movement per se—as its framework to integrate justice and environmentalism. (In this planning worldview, environmental justice would be an important subset of the larger field of urban sustainability.)

The urban planning field has therefore sought to construct its own distinctive hybrid of these two movements. These open questions led the University of Michi- 
gan Urban Planning Program to host a symposium in October 2012: "Sustainability \& Social Justice: Conflicting Urgencies," bringing together scholars, activists and professionals working both in the U.S. and abroad. ${ }^{1}$ Had this been primarily a philosophical exercise, we might have approached the task as a definitional one: exploring shared meaning and difference in the semantics and etymology of "sustainability" and "justice." Instead, planning is a largely pragmatic field where theoretical meaning is constructed through community engagement and professional practice, and definitions are inscribed in zoning codes, policies, plans and land use law. We therefore sought to understand sustainability and justice by examining how these terms are used in public, in government, in markets and in the daily practices of planners. The ecological-equity integration would therefore be less a linguistic synthesis and more a professional, cultural and political synthesis.

This paper is not a comprehensive reportage of either the planning program's efforts or the symposium's proceedings, though both richly inform this essay and I am indebted to the insights of colleagues and symposium participants. Instead, I use these specific experiences as an entrée into the broader encounter between social justice and sustainability. These efforts (in the classroom, in planning practice, in public debate and in academic literature) illustrate both the power and contradictions of bringing these two social movements together. I make three specific arguments. First, though efforts to bring social justice and sustainability together are crucial, an impatient rush towards an easy, seamless synthesis will lead to a premature closure of the debate, obfuscating the richer possibilities of the encounter that arise through sustained, creative tension. Second, the marriage of social justice and sustainability, as currently constituted, is not a marriage of equals. (And the unspoken third player in this coalition, the imperative of economic growth, further imbalances the mix, allying itself with middle-class sustainability over redistributive justice.) Third, despite the familiar criticisms of being vague, ambiguous, not operationalizable or co-opted, the idea of sustainability stalwartly remains a recurring and compelling theme for most urban planners. The idea endures in large part because it has evolved over the past two decades through its very engagement with social justice and economic development, grounded in the ongoing practice of planning and design-

1. The author thanks the three outside reviewers and the journal editorial staff, in particular Nick Rajkovich, for their generous comments and patient encouragement. Thank you also to the fall 2012 Symposium participants whose collective ideas helped trigger this paper: Adhir Kackar, Larissa Larsen, Doug Kelbaugh, John Randolph, Tom Angotti, Khalil Ligon, Shelley Poticha, June Thomas, Majora Carter, Hunter Morrison, Richard Norton, Emily Talen, Bill Anderson, Margaret Dewar, Harley Etienne, Clara Irazabal, Jonathan Levine, Joe Grengs, Scott Campbell, Monica Ponce de Leon. Videos of the symposium sessions are posted online at the Taubman College Vimeo Channel: http://vimeo.com/album/2135261. 
ing a sustainable built environment. Rather than undermining sustainability as a concept, these tensions with justice and economic development have reinvigorated sustainability and kept the term relevant and vibrant.

\section{A Creative Tension, Not a Premature Synthesis}

Though the initial impulse was to title the urban planning symposium "Integrating sustainability and social justice," the organizing committee wisely avoided this temptation of a tidy convergence of the two ideas. The final title, "Sustainability \& Social Justice: Conflicting Urgencies," represented more than a semantic shift. The subtitle articulated both the substantive, unresolved tensions between these two priorities and the divergent arguments over which of the two represented a more pressing problem for society to tackle. The title squarely acknowledged conflict and scarce resources: what trade-offs of time, money, land and political capital should we allocate to each priority? The term "conflicting urgencies" also acknowledged a disagreement over sequencing: that is, should society first seek social justice and then strive for sustainability, or the reverse? Is achieving one a prerequisite of achieving the other? To casually speak of "balancing" social justice and sustainability would have invited easy platitudes and obscured the structural conflicts between the two movements. Political movements don't usually "balance"; they instead lobby, fight, claim the political center, marginalize opponents and build alliances.

This intentional partition of sustainable development and social justice does run the risk of reinforcing the very schism that the symposium was aiming to overcome. But as the history of race, gender and other social identities teaches us, sometimes you first need to acknowledge and confront difference before you transcend difference. A hasty synthesis of social justice and sustainability will often be unsatisfactory: it provides a short-term sense of solution, but truncates further exploration. Instead, we should keep the sustainability-social justice debate open, evolving and in a creative tension. The two impulses arguably do not arise from the same social histories or institutions, and therefore cannot-at least for now-be merged without important stakeholders losing out. The pathway to reconciling social justice and environmental sustainability is one that explicitly recognizes both the significant, deep conflicts between the two forces and the urgent need to find innovative, ongoing social and technological pathways forward (Campbell 1996).

This strategy of seeking solutions through recognizing and reconciling diverse claims and interests has a strong tradition in urban planning, from the rejection 
of a unitary public interest by pluralist, advocacy planners (Davidoff 1965) to the current Habermas-inspired communicative action planners, who collaboratively explore planning solutions through diverse public participation (Healey 2006; Innes 1998; Forester 1999). The outcome is not a forced, monolithic solution, but rather a more inclusive set of solutions. It is the search for common ground where advocates of social justice and environmental sustainability can craft shared-or at least compatible - strategies for retrofitting existing landscapes and designing new ones.

Urban planning's multiple priorities (social justice, sustainability, economic development, aesthetics, etc.) arise both from the complex interests of the contemporary city and from the field's amalgamated historical origins. Within planning, the social justice movement draws significantly on the civil rights, labor, feminist and community development traditions as well as the advocacy planning/community activist tradition of the 1960s and the equity planning tradition of the 1970s, and ultimately on planning's roots in the Progressive Era and housing reform efforts. Sustainability planning draws on environmental science, ecology, land use and physical planning, linked to planning's separate set of historical roots in conservationism, greenbelt planning, landscape architecture, urban parks, and river basin planning. As a result, each movement has historically developed its own distinctive language, methods, and values. For environmental sustainability, a core distinction is city vs. country (the boundaries between society and nature, between the built and unbuilt); for social justice, the core distinction is often between city and suburb, between the global North and South, between the socially marginalized and the elites.

The two paradigms also have divergent conceptions of capital: social justice advocates decry the extreme concentration of economic capital among a small elite, and the uneven public investment in human capital (education and labor), all leading to jarring inequalities of social capital (the quality of communities and their institutional networks) across neighborhoods and cities. By contrast, sustainability advocates criticize the exploitation of natural capital through excessive rates of resource extraction and waste disposal.

Furthermore, the divergent sense of justice is rooted in differing views of exploitation: either the exercise of power by one group over another (social injustice), or the hubris of exerting excessive power over nature (unsustainability). Finding common ground will thus mean finding a common language: translating conceptions of time, justice, place, land, and equity from social justice to environmental sustainability and back again. Planners can already draw on existing work that expands conceptions and measurements of capital, of environmental value, economic activity (e.g., a "green GDP" measure), of resource use intensity (e.g., 
ecological footprint) and of environmental human rights. Public health and the growing use of Health Impact Assessments (HIAs) also provide common ground and a shared tool.

The co-equal merging of these two movements will therefore not be a straightforward, inevitable process, though there is a lot to work with. The planning field, like other disciplines, runs the risk of privileging one position and marginalizing the other. The urban planning symposium illustrated both the obstacles and the potentials of this collaboration. Nearly all invited speakers agreed to come to Ann Arbor, showing an enthusiastic commitment to the social justice/sustainability collaboration. That said, the structure and syntax of the two sets of discussions didn't always overlap as much as the organizers had hoped. They instead represented two distinct discussions: at worst like two ships passing in the night, at best like counterpoint, and most often like overlapping but unsynchronized storylines. One group spoke of civil rights, poverty, discrimination, underdevelopment, racism, empowerment, disenfranchisement, violence, access; the other spoke of climate change, ecological footprint, living lightly, green design, clustered development, renewable resources, innovative ecological technology. Session participants often struggled to address both themes simultaneously (just as it is hard for most humans to speak two languages at one time). And the transition from one panel session to the next was at times a jarring shift in narrative style, with changing rhetorical strategies and evidentiary claims about why their cause (be it farmland loss, urban unemployment, global climate change, struggling central city schools) was particularly urgent. Yet I also observed a genuine effort to link the two discussions, and perhaps more importantly, a mutual respect for and attentiveness to each other's work and stories. Rather than observing a common language, we might instead, at least in the short run, work towards a bilingualism between the two traditions. And this might be enough of a collaboration for now.

Some speakers were able to speak both languages more fluently than others. In these instances, the speaker had strong roots in one tradition (such as civil rightsbased community development advocacy) and then actively engaged the other theme (environmentalism) over a sustained period of time. Several speakers used this "code-switching," including Majora Carter as she spoke about her earlier work with Sustainable South Bronx. This suggests an important lesson: bringing environmentalism and social justice together (in an expansive sense of sustainability) takes conscious effort, hard work, sustained engagement and active building of coalitions over many years - often working squarely from one tradition and then consciously, actively working towards the other. For most, this ability to fluently code-switch 
between environmentalism and social justice won't happen through passive parallel engagement, or through simply crafting a manifesto that combines language of both. And making a general statement that "true sustainability requires social justice" (or the converse) is mere wishful thinking in the absence of further logical proof or evidence - though Oden (2010) makes a good case for an emphasis on equity as a way to expand the political base for sustainability.

So, though we work hard to align these two worlds more closely, powerful forces relentlessly pull social justice and environmental protection apart due to the contradictory pressures and political alliances of urban development, driving a wedge between the two movements (see Figure 1). Scholars and activists require an equal or even greater force to bring them together. The prevailing political strategy of many modern industrial nations has been to accelerate greater social equality through economic growth and urban land expansion (though Henry George (1879) reminds us that great poverty despite great prosperity is the paradox of industrial society). This strategy is a dynamic of the social welfare state and its redistributive institutions of taxation, organized labor, public provision of infrastructure, housing subsidies, and mass consumption of cheap goods, fuel and other natural resources. Despite overt conflict between capital and labor-and rich and poor-both sides also share an overlapping interest in economic growth and in promoting at least a partial program of economic redistribution. As a result, the traditional reliance of social justice movements on economic growth to fund and provide broad political support for redistributive justice (i.e., to get a larger slice of the pie, bake a larger pie) will undermine efforts to build stronger alliances between social justice and environmentalism - at least the environmentalism that seeks to impose limits to growth and resource use. (This reliance on equity-through-growth also points to the obstacles faced by traditional environmental justice strategies to achieve a broader economic justice).

This conundrum also points towards the urgency to develop alternative political strategies to achieve greater equity in an era of sustainability-pathways to social justice that are not reliant on the continual expansion of resource extraction, material consumption and conversion of green space into urbanized areas. This will be both an ideological and a political challenge, linked to the further decoupling of economic growth and resource extraction through both greater natural resource efficiencies and shifting a greater share of GDP towards relatively non-material consumption (e.g., education, services, health care, culture, arts). 


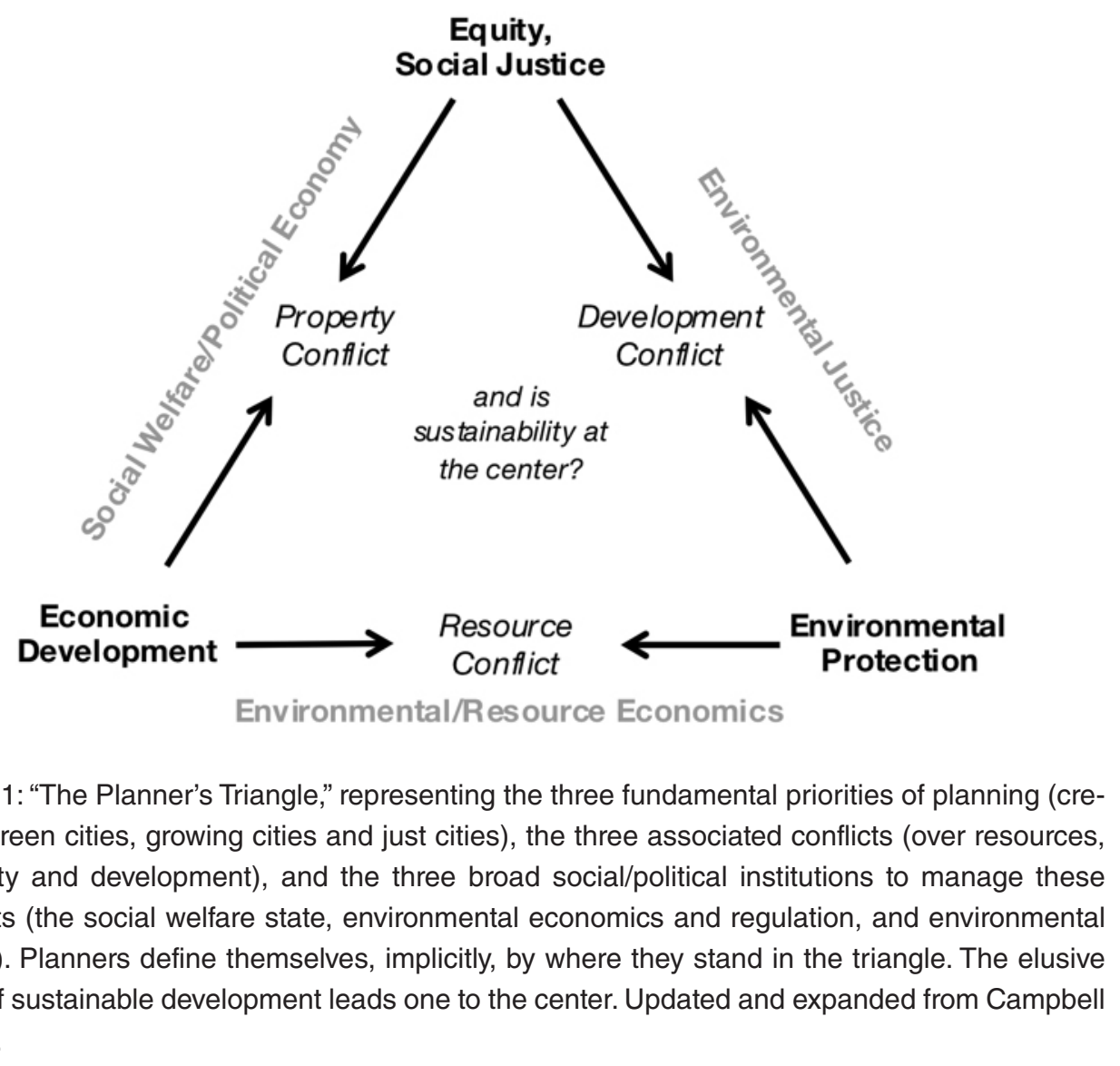

Figure 1: "The Planner's Triangle," representing the three fundamental priorities of planning (creating green cities, growing cities and just cities), the three associated conflicts (over resources, property and development), and the three broad social/political institutions to manage these conflicts (the social welfare state, environmental economics and regulation, and environmental justice). Planners define themselves, implicitly, by where they stand in the triangle. The elusive ideal of sustainable development leads one to the center. Updated and expanded from Campbell (1996).

\section{The Merger of Unequals}

"If we say only that we have mixed our labour with the earth, our forces with its forces, we are stopping short of the truth that we have done this unequally: that for the miner and the writer the mixing is different, though in both cases real; and that for the labourer and the man who manages his labour, the producer and the dealer in his products, the difference is wider again. Out of the ways in which we have interacted with the physical world we have made not only human nature and an altered natural order; we have also made societies. .... If we talk only of singular Man and singular Nature we can compose a general history, but at the cost of excluding the real and altering social relations" (Williams 1980, 84).

The meeting of environmental sustainability and social justice is often regrettably the meeting of unequals. By unequal I do not refer to the relative merit of the two 
priorities, but instead to the ill-matched political strengths of the two movements and the ability of each movement to prevail in struggles over access to land, the use of natural resources, and the distribution of environmental advantages and dangers. Does society as a whole value environmental protection more than social justice (and value economic development most of all)? This assertion is intuitively compelling but nearly impossible to conclusively measure. Rational choice theory would support the observation that the elite and middle-class segments of society have historically engaged the environmental movement with greater consistency and resources than they have engaged the social justice movement. The reasons are complex, but a simple explanation is that environmentalism —or at least the prevalent practice of anthrocentric, resource conservation-more directly serves the material interests of the privileged by restricting present-day consumption to increase future profits through resource extraction (Oden 2010). By contrast, the privileged have long held a conflictual, ambivalent relationship towards social justice, alternately driven by paternalism, opposition, fear, and altruism going back to the Victorian anti-poverty efforts and earlier. (Not surprisingly, more radical, anti-growth, ecocentric environmentalisms find far less support among the economic elites.)

Such a conclusion may strike some as resigned or pessimistic. However, understanding these structural barriers may well be a necessary pre-requisite to a systemic understanding of the uneven engagement of sustainability and social justice and consequential steps towards reform. Though sometimes environmental and social justice movements find a productive common ground, more often these two clash, with fault lines emerging along social and economic class lines. Acknowledging how the larger social structure constrains the opportunities for solidarity across the environmental/social justice divide also points towards strategies to make progress within these constraints and to expand the range of collaborative, win-win opportunities.

Advocates of social justice who engage sustainable urban planning pose the pointed question: what is to be sustained, and for whom? This differentiation is central to the social justice engagement with sustainability, whether framed as a formal class analysis, as interest group politics, as race $\&$ gender categories, or as spatial divisions (this last approach is of particular relevance to urban planning). This disparity happens on at least two levels: between the rich and poor within metropolitan areas (once between the pauperized rural area and the rich city, now more typically between the urban poor and suburban middle-class), and across rich versus poor nations. This emphasis on the distributional implications arises from the worldview that just as goods and services are systemically distributed unequally, 
so too are environmental privileges and burdens. Sustainability efforts will invariably aid some groups more than others, even to the point of harming those with the least amount of power to shape the politics of sustainability (Marcuse 1998). This unevenness may well lead to tensions between mainstream sustainability and environmental justice efforts.

This disparity highlights a tension within the sustainability movement: is it a universal movement that advances the interests of all parties, or does it instead serve the narrower interests of specific groups and classes? Yes, most mainstream environmentalists do assert the universality of sustainability: that it should be applicable to all members of society. Yet this stated universality is often undercut by on-theground practices. We should therefore not be surprised when the sustainability narrative is "captured" and defined by powerful interests. The result is the "sustaining" of the privileges and lifestyles of the elites and middle class, which makes sustaining the livelihoods of the poor even more difficult. A troubling development is the new alliances between economic elites and environmentalism, building exclusionary "green bubbles for rich people" (Tom Angotti, symposium speaker).

This self-interested version of "sustainability" may strike many as a perversion of the true spirit of sustainability. Indeed, this exclusionary political strategy reduces "sustainability" to a narrow process of replicating and protecting a middleclass environmental quality of life, often hidden behind real or de facto gates in elite walkable communities reinforced through exclusionary zoning surrounded by green buffers. (And we see here how inequality is not just passively mapped onto space, but instead how these geographic spaces - and the associated land use markets and regulations - are active instruments to magnify and reinforce these inequalities.) This divide undermines efforts to use sustainability as a unifying movement to promote greater social equality across economic classes.

Some may link this corruption of the term sustainability to "greenwashing," eco-branding, and other superficial misappropriations. But it has a deeper dynamic, linked to the structural functioning of urban and global economic systems. Our complex economic networks are highly specialized, differentiated, segmented landscapes, built upon an elaborate spatial division of labor, resource extraction, manufacturing, consumption and waste disposal. This geographic division creates a highly uneven, segregated map of rich and poor, elites and exploited, pristine and polluted, formal and informal, all connected through trade. This ability to import resources, export pollution and reinforce boundaries between the haves and have-nots allows for the growing spatial separation of environmental quality (the benefits of consuming nature) versus environmental impact (the costs). This spatial 
and social divide undermines the idea of sustainability as a collectively shared and experienced social project. Put another way, incorporating social justice into the sustainability movement will be far more effective if the movement directly engages the way that structural and territorial inequalities reinforce this subversion of the universal, shared sustainability idea. Otherwise, the persistent danger is that the rhetoric of sustainability will be used to preserve islands of green privilege within this uneven landscape rather than working to overcome them. And I am afraid that this tension about sustainability won't quickly vanish.

Engaging this class-specific view of sustainability also frees us from the standard society vs. nature dichotomy (e.g., jobs vs. the environment) and places us squarely into the world of pluralistic politics. The nature-human dichotomy is misleading: it obscures social relations and inequality, and implies that there is an intrinsic, universal relationship between society and Earth. This is not to reject outright the existence of some widely shared human tendency to exploit and modify nature to improve the human condition. Indeed, Hobbes, Rousseau and others have constructed theories of political philosophy based on their forceful assumptions about the intrinsic nature of humans. That said, I would argue that the modern sustainability movement does not require the identification of the underlying, essential relationship between humans and nature as a prerequisite to its efforts. In any case, the current scientific and urban professional community is highly skeptical of (at least explicitly) essentialistic assumptions about human/Earth interactions as a foundation for policy analysis (though I can imagine that making such assumptions would be central in discussions about spiritual paths towards sustainability).

Even identifying social class-specific relationships to nature-and to the ideas of sustainability - is not straightforward. Is the farmer, the lumberjack, the hiker, the backyard gardener, the coal miner or the city subway rider "closer" to nature? The poor in rapidly developing countries are often the immediate agents of environmental damage — as miners, tree cutters, poachers, etc. (Evans 2002). But they are often either working at the behest of the elites or feel forced into this labor due to poverty and few other easy options. This creates a tension between the immediate search for livelihoods and the longer-term consequences of poverty and limited control over resources. This goes to the core contradiction of development policy, i.e., the 'development conflict' between efforts to increase social equity and protect the environment simultaneously (see Figure 1). One might go further and call this the "poverty-sustainability" conundrum, in which efforts to alleviate deep poverty in global megacities collide with efforts to reduce greenhouse gases and other global- 
scaled environmental crises. (In effect, the developed nations would be asking the poorer nations to restrain themselves in an extended state of underdevelopment to save the Earth.) There has long been a "sustainability crisis" in poor communities. "It is only when their environmental problems also became those of the rest, of the better off, that the cry finally went up" (Olpadwala and Goldsmith 1992, 630).

For our discussion here, the consequence of this unevenness is a disconnect between what sustainability means for the middle class (e.g., green space for recreation, nature as an amenity and visual backdrop, etc.) and for the poor (e.g., the slum dweller's daily search for food, water and work and fear of forced eviction from the land). The rhetoric of middle-class sustainability usually trumps the claims for basic needs for the poor. Incorporating the livability of cities for the poor as another core question of sustainability will be a huge step forward. In this light, integrating environmental sustainability and social justice is not simply ornamenting the existing sustainability narrative with a few gracious phrases from the social justice movement. Instead, it means breaking out of the middle-class sustainability of privileged abundance and writing a sustainability of disenfranchised scarcity, and being prepared to deal with the inevitable conflicts that arise from the collision of these two classes of sustainability.

\section{Evolution of the Sustainability Idea in Planning}

I conclude this essay by asking why sustainability remains a central, persuasive idea for many urban planners-despite the commonplace criticisms that the idea is nebulous, imprecise, corrupted or difficult to implement. Planners have explicitly engaged the idea of sustainability for several decades (and have tacitly engaged sustainability-like concepts for even longer), so there must be something enduringly compelling about it. Indeed, were the idea of sustainability instead easy and unambiguous, it wouldn't be so powerful; we would simply have implemented sustainability practices and moved on to the next task. The complex challenges of defining, measuring, negotiating and putting sustainability into practice should not discourage us, but should rather be a signal that sustainability is the big prize worth pursuing.

The sustainability concept has endured in planning in large part because it has not stood still. Instead, it has evolved over the past two decades; had the idea remained static and inflexible, it probably would not have been assimilated into 
planning scholarship and professional practice. True, this flexibility can also lead to chameleon-like opportunism, with the term "sustainability" too readily attached to plans, policies, development projects and scholarly research titles without a substantive commitment to environmental transformation (a criticism made forcefully by Gunder 2006). But flexibility has also been productive, creating a broad base of support and interest, allowing multiple parties with divergent priorities all to engage and embrace sustainability as their own. Gro Brundtland and others have called this a "constructive ambiguity" - akin to diplomats' use of an intentionally ambiguous term to achieve an initial common ground and to avoid a premature breakdown in negotiations over specifics. (Skeptics might instead call this a "deceptive ambiguity.") ${ }^{2}$ The term "sustainability" has attracted a wide array of otherwise adversarial parties who would likely not have come to a public meeting, hearing or design event had the term "environmental" or "conservation" been used. Sustainability has retained this "big tent" organizing function, and this may explain why most planners continue to employ the term.

Sustainability also endures because it taps into planning's core ideas and values, and links well to other dominant themes in contemporary planning: fighting sprawl, compact cities, new urbanism, greenbelts, walkable urbanism, transit-oriented development, reclaiming the central city. Sustainability becomes a central narrative and organizing logic for these various planning efforts. Sustainability provides a larger legitimacy of purpose (and rationalization) for these efforts as serving the long-term public interest. The idea of sustainability is also sympathetic to prevalent beliefs among planners: that resource politics are often too myopic and society should instead take a long-term, multi-generational view into the future; that the impacts of development (good and bad) are interactive and cumulative; that much of environmental harm arises from externalities (and therefore society should strive more for "true-cost pricing"); that there are valuable public spaces ("commons" in both the city and the wild) worthy of collective protection; and that solutions should be both interdisciplinary and tied to land management and spatial planning.

The planning profession may well claim, with credible evidence, that it has engaged in sustainability (by other names) since long before the term arose (going back to the work of Patrick Geddes, Ebenezer Howard, Lewis Mumford and others a century ago), and that the current emphasis on "sustainability planning" is sim-

2. Whether sustainability is a constructive or a manipulative/deceptive ambiguity plays off a long political argument about whether incremental reform leads to real cumulative progress or instead co-opts, diverts and ultimately thwarts such progress. We can't resolve this larger political debate regarding revolutionary vs. reformist change here. 
ply old wine in new bottles. This is partly true. But sustainability has given these older planning ideas new currency and placed issues of reconciling environmental, economic and social conflicts at the center of the profession's mandate—something that older versions of "environmental planning" were not able to achieve.

Planners also continue to engage sustainability even after the initial novelty waned because the idea strategically links planning to other disciplines. Sustainability is creating a common language and set of practices (measures, methods, goals) between the relatively small field of planning and the larger world of environmental management, public health, ecological science, public policy, and other allied fields. Planning is historically an interdisciplinary field (with roots in architecture, landscape architecture, housing reform and applied social sciences). The current engagement with sustainability has expanded these cross-disciplinary connections, enriched planning with an infusion of outside ideas, and also helped planning better export its work to other fields. Sustainability has also provided an expanded set of professional and scholarly tasks that planning, as still a relatively small and underfunded field, uses to bolster its claims of legitimacy and relevance to university leaders, city officials, and funding agencies. Planning is not unique here; other fields have expanded their domains as well to include sustainability as one of their "core" tasks. Though each field may claim part of sustainability as uniquely its own and assert its own discipline-specific comparative advantage in addressing sustainability, no one field has been able to fully "capture" the idea. And that is part of sustainability's power as an idea and set of challenges; it has created a commons for research and professional exploration, beyond the boundaries of individual disciplines.

Sustainable planning has indeed evolved and matured in the years since the 1987 Brundtland Report (World Commission on Environment and Development 1987). The term has largely gone mainstream (even if practice hasn't always caught up), to the point where its dutiful mention elicits more yawns than raised eyebrows. The term is part of the lingua franca of the field, permeating planning curricula, scholarly writings, and local plans. Rather than remaining partitioned in one specialization within planning (e.g., environmental planning), the ideas and practices of sustainability increasingly find their way into the other planning specializations (transportation, economic development, housing, international development, etc.). There are fewer quibbles about and more tolerance of sustainability's multiple definitions and its fuzzy, unbounded breadth than before.

True, planners invariably run the risk of overselling sustainability as a unifying paradigm for planning's widespread, unruly branches. During a previous planning 
era of ambitious disciplinary expansion, Aaron Wildavsky (1973) quipped, "if planning is everything, maybe it's nothing." These days, one might be tempted to smugly substitute "sustainability" for "planning" in that 1970s quotation. But I observe that many planners are well aware of this trap of overgeneralization and astutely strive to continuously refine, redefine and customize the idea of sustainability for local contexts and audiences. Sustainability does create solidarity of environmentalists and a network of shared ideas, but the idea doesn't export without translation and local adaption. During the Sustainability/Social Justice symposium, Larissa Larsen spoke of challenges of using the idea in places like Appalachia (where it just did not seem to fit), Hunter Morrison spoke of the difference in using sustainability in his own declining northeast Ohio (as compared to growing places like the Sunbelt), and Emily Talen argued that to make sustainability usefully tangible, it must be rooted in specifics and everyday practices (i.e., planning and designing the built environment).

The most nimble of planners are thus able to successfully navigate the tension between the universality and the militant particularism of the sustainability idea. Straddling this global/local tension is a constant disciplinary challenge for planning, but also an area where planning has much experience and expertise. And global climate change has only made this tension more urgent: planners are now acutely aware that their local efforts to reduce building energy use, vehicle miles traveled (VMT), impervious surfaces and heat island effects are a small but cumulatively essential part of a larger global effort. Climate change has made local sustainability not only more urgent, but also more focused: it is the game changer that has forced planning (and other disciplines) to rework the long-term goals of sustainability.

Finally, the sustainability narrative remains vibrant and vital within planning because it has evolved over the past two decades through its very engagement with social justice, grounded in the ongoing practice of planning and designing both a greener and more equitable built environment. It is this productive collision of the environmental and community activist movements - and the ongoing efforts to recombine and reconcile these two traditions with their divergent histories, values and communities - that has fueled the thoughtful advancement of sustainability planning. The sustainability movement will continue to be powerful as long as it creates a commons where planners, their allies and their adversaries can debate the hard questions, negotiate compromises in the distribution of natural and human wealth, and creatively explore alternative urban futures. 


\section{References}

Agyeman, Julian. 2005. Sustainable Communities and the Challenge of Environmental Justice. New York: New York University Press.

Bryant, Bunyan I. 1995. Environmental Justice: Issues, Policies, and Solutions. Washington, D.C.: Island Press.

Bryant, Bunyan, and Paul Mohai. 1992. Race and the Incidence of Environmental Hazards. Boulder, CO: Westview Press.

Bullard, Robert D. 1994. Unequal Protection: Environmental Justice and Communities of Color. San Francisco: Sierra Club Books.

Campbell, Scott. 1996. "Green Cities, Growing Cities, Just Cities? Urban Planning and the Contradictions of Sustainable Development." Journal of the American Planning Association 62 (3): 296-312. http://dx.doi.org/10.1080/01944369608975696

Davidoff, Paul. 1965. "Advocacy and Pluralism in Planning." Journal of the American Institute of Planners 31 (4): 544-555. http://dx.doi.org/10.1080/01944366508978187

Evans, Peter. 2002. Livable Cities? Urban Struggles for Livelihood and Sustainability. Berkeley, Los Angeles, London: University of California Press.

Forester, John. 1999. The Deliberative Practitioner: Encouraging Participatory Planning Processes. Cambridge, MA: MIT Press.

George, Henry. 1879. Progress and Poverty; An Inquiry into the Cause of Industrial Depressions, and of Increase of Want with Increase of Wealth--The Remedy. Author's ed. San Francisco: W. M. Hinton $\&$ Co. Printers.

Gunder, Michael. 2006. “Sustainability: Planning's Saving Grace or Road to Perdition?” Journal of Planning Education and Research 26:208-221. http://dx.doi.org/10.1177/0739456X06289359

Healey, Patsy. 2006. Collaborative Planning: Shaping Places in Fragmented Societies, 2nd ed. Basingstoke, Hampshire ; New York: Palgrave Macmillan.

Hofrichter, Richard. 1993. Toxic Struggles: The Theory and Practice of Environmental Justice. Philadelphia: New Society Publishers.

Innes, Judith E. 1998. "Information in Communicative Planning." Journal of the American Planning Association 64 (Winter): 52-63. http://dx.doi.org/10.1080/01944369808975956

Marcuse, Peter. 1998. "Sustainability is not enough." Environment and Urbanization 10 (2):103111. http://dx.doi.org/10.1177/095624789801000201

Oden, Michael D. 2010. "Equity: The Forgotten E in Sustainable Development." In Pragmatic Sustainability: Theoretical and Practical Tools, edited by Steven A. Moore, 31-49. London; New York, NY: Routledge.

Olpadwala, Porus, and William Goldsmith. 1992. "The Sustainability of Privilege: Reflections on the Environment, the Third World City, and Poverty." World Development 20 (4): 627-640. http://dx.doi.org/10.1016/0305-750X(92)90050-6

Taylor, Dorceta E. 2009. The Environment and the People in American Cities, 1600s-1900s: Disorder, Inequality, and Social Change. Durham: Duke University Press.

Wildavsky, Aaron. 1973. "If Planning is Everything, Maybe It's Nothing." Policy Sciences 4 (2): 127-153. http://dx.doi.org/10.1007/BF01405729

Williams, Raymond. 1980. Problems in Materialism and Culture: Selected Essays. London: NLB.

World Commission on Environment and Development. 1987. Our Common Future. Oxford: Oxford University Press. 